\title{
Interleukin-6 Predicts Recurrence and Survival Among Head and Neck Cancer Patients
}

\author{
Sonia A. Duffy, PhD, RN ${ }^{1,2,3,4}$ \\ Jeremy M.G. Taylor, $\mathrm{PhD}^{5}$ \\ Jeffrey $\mathrm{E}$. Terrell, $\mathrm{MD}^{1}$ \\ Mozaffarul Islam, $\mathrm{PhD}^{1}$ \\ Yun Li, Ms ${ }^{5}$ \\ Karen E. Fowler, $\mathrm{MPH}^{3}$ \\ Gregory T. Wolf, MD ${ }^{1}$ \\ Theodoros N. Teknos, MD ${ }^{1}$ \\ ${ }^{1}$ Department of Otolaryngology, University of \\ Michigan Medical School, Ann Arbor, Michigan. \\ ${ }^{2}$ Department of Psychiatry, University of Michi- \\ gan Medical School, Ann Arbor, Michigan. \\ ${ }^{3}$ Ann Arbor VA HSR\&D Center of Excellence, VA \\ Ann Arbor Healthcare System, Ann Arbor, Michi- \\ gan. \\ ${ }^{4}$ School of Nursing, University of Michigan, Ann \\ Arbor, Michigan. \\ ${ }^{5}$ Department of Biostatistics, University of Michi- \\ gan School of Public Health, Ann Arbor, Michigan.
}

See editorial on pages $671-3$, this issue.

Supported by the U. S. National Institutes of Health through the University of Michigan's Head and Neck Specialized Program of Research Excellence (Grant Number P50 CA97248).

We thank Suzan McCormick, Chelsea Hughes, Elizabeth Knight, Zheng Yuan, Scott McLean, and the staff of the University of Michigan Hospital, Ann Arbor VAMC, and Henry Ford Hospital Otolaryngology clinics for their assistance with recruitment, data collection, and data analysis. The authors would also like to thank the patients that generously participated in this study.

Address for reprints: Sonia A. Duffy, PhD, RN, University of Michigan Department of Otolaryngology, Ann Arbor VA HSR\&D Center of Excellence, VA Ann Arbor Healthcare System (11H), P.0. Box 130170, Ann Arbor, Ml 48113-0170; Fax: (734) 845-3250; E-mail: bump@med.umich.edu

Received October 9, 2007; revision received December 14, 2007; accepted January 7, 2008.
BACKGROUND. Increased pretreatment serum interleukin (IL)-6 levels among patients with head and neck squamous cell carcinoma (HNSCC) have been shown to correlate with poor prognosis, but sample sizes in prior studies have been small and thus unable to control for other known prognostic variables.

METHODS. A longitudinal, prospective cohort study determined the correlation between pretreatment serum IL-6 levels, and tumor recurrence and all-cause survival in a large population ( $\mathrm{N}=444$ ) of previously untreated HNSCC patients. Control variables included age, sex, smoking, cancer site and stage, and comorbidities. Kaplan-Meier plots and univariate and multivariate Cox proportional hazards models were used to study the association between IL-6 levels, control variables, and time to recurrence and survival.

RESULTS. The median serum IL-6 level was $13 \mathrm{pg} / \mathrm{mL}$ (range, 0-453). The 2-year recurrence rate was $35.2 \%$ (standard error, $2.67 \%$ ). The 2 -year death rate was $26.5 \%$ (standard error, 2.26\%). Multivariate analyses showed that serum IL-6 levels independently predicted recurrence at significant levels [hazard ratio (HR) $=1.32 ; 95 \%$ confidence interval $(\mathrm{CI}), 1.11$ to $1.58 ; P=.002$ ] as did cancer site (oral/sinus). Serum IL-6 level was also a significant independent predictor of poor survival ( $\mathrm{HR}=1.22$; 95\% $\mathrm{CI}, 1.02$ to $1.46 ; P=.03$ ), as were older age, smoking, cancer site (oral/sinus), higher cancer stage, and comorbidities.

CONCLUSIONS. Pretreatment serum IL-6 could be a valuable biomarker for predicting recurrence and overall survival among HNSCC patients. Using IL-6 as a biomarker for recurrence and survival may allow for earlier identification and treatment of disease relapse. Cancer 2008;113:750-7. (ㄷ 2008 American Cancer Society.

KEYWORDS: head and neck neoplasms, interleukin-6, cytokines, recurrence, survival.

D espite improvements in diagnosis and local disease management, long-term survival rates in patients with head and neck squamous cell carcinoma (HNSCC) have not increased significantly over the last 30 years, and are among the lowest of the major cancers. Because recurrence of HNSCC is strongly associated with poor survival, earlier identification of tumor relapse through the use of assays for molecular markers could be beneficial in allowing early detection and treatment when recurrences are small, more easily resected, and potentially more curable. Likewise, if patients at highest risk for recurrence are identified, they could be targeted for more intensive surveillance and chemoprevention therapy. In this study, we prospectively evaluated the relationship between pretreatment levels of serum interleukin (IL)-6, and tumor recurrence and survival among previously untreated patients with HNSCC. 
IL-6 is a multifunctional cytokine that was originally identified by its ability to drive the differentiation of B-lymphocytes into antibody-producing plasma cells. It was thought to be produced by several types of inflammatory cells and fibroblasts, playing a central role in host defense mechanisms. ${ }^{1,2}$ Since that discovery, IL-6 has been found to be a potent proinflammatory cytokine, which in conjunction with IL-1 and tumor necrosis factor can initiate the innate immune response by inducing the acute phase of inflammation., ${ }^{3,4}$ Furthermore, IL-6 has recently been implicated in malignant transformation of epithelial cells and in tumor progression. Under the influence of the transcription factor nuclear factor kappa b, its expression can be induced in several types of malignancy. ${ }^{5}$ Specifically, HNSCC has been shown to express high levels of IL-6, and HNSCC cells are more apt to invade and metastasize in an environment rich in this cytokine. ${ }^{6,7}$ IL-6 can also promote immune unresponsiveness and induce cachexia, both of which are observed in HNSCC patients who have a poor prognosis. ${ }^{8-10}$ IL-6 can also trigger signal transduction and activator of transcription (STAT)-3 phosphorylation, which is associated with various human cancers and commonly suggests poor prognosis related to apoptotic as well as proliferative effects. ${ }^{11-14}$

In gastric, renal, prostate, ovarian, and breast cancer, increased levels of serum IL- 6 have been associated with poor prognosis, ${ }^{15-19}$ but similar studies in head and neck cancer are lacking. In a small study $(\mathrm{N}=34)$, De Schutter et al illustrated that pretreatment serum IL-6 levels in HNSCC patients correlated with radioresistence, local control, disease-free survival, and overall survival. ${ }^{20}$ Other small case-control studies in head and neck cancer alluded to similar findings, but universally the authors suggest that larger studies are needed. ${ }^{7,21,22}$ As a result of such suggestions, a longitudinal study was designed to prospectively determine the correlation between pretreatment serum IL-6, and tumor recurrence and all-cause survival in a large population $(\mathrm{N}=444)$ of HNSCC patients, controlling for other prognostic indicators.

\section{MATERIALS AND METHODS}

This was a prospective cohort study of patients enrolled in the University of Michigan Head and Neck Cancer, Specialized Programs of Research Excellence. The primary explanatory variable was pretreatment serum IL-6 levels. Control variables were age, sex, smoking, cancer site, cancer stage, and comorbidities. The outcome variables were tumor recurrence and all-cause survival.

\section{Study Population}

Research assistants approached 869 newly diagnosed patients with HNSCC for participation in this study. Excluded were those 1) $<18$ years of age, 2) pregnant, 3) non-English speaking, 4) psychiatrically or mentally unstable (such as suicidal ideation, acute psychosis, or dementia), or 5) with nonupper aerodigestive tract cancer (such as thyroid or skin cancer). Of those approached, 638 (73\%) were eligible and agreed to participate. For this analysis, those with recurrent disease or previously treated HNSCC were also excluded $(\mathrm{n}=57)$. An additional 137 subjects did not have a pretreatment serum sample, which left a sample size of 444 .

Institutional review board approval was received from the 3 study sites: the University of Michigan Medical Center, Veterans Affairs (VA) Ann Arbor Healthcare System, and Henry Ford Health System. Recruitment began in January 2003. Patients were censored as having a recurrence or not at their last annual chart review, and as being dead or alive as of February 1, 2007.

\section{Procedure}

Research assistants recruited patients to the study in the waiting rooms of otolaryngology clinics by obtaining signed informed consent and providing a written survey that had questions on demographics and health behaviors. A medical record audit was also conducted. Pretreatment blood was drawn into coded sterile red-top vacuum tubes.

\section{Measures}

Explanatory variable - serum IL-6 analysis

Serum samples were kept frozen at $-80^{\circ} \mathrm{C}$ and then thawed shortly before determination of IL- 6 levels. Quantification of serum IL-6 levels was performed using an enzyme-linked immunosorbent assay (ELISA) performed in triplicate using a commercially available ELISA kit (Quantikine Human IL-6 Immunoassay, R\&D Systems, Minneapolis, MN). Briefly, serum samples from all patients were incubated for 2 hours at room temperature in duplicate $(100 \mu \mathrm{L})$ on microtiter plates coated with a monoclonal antibody specific for IL-6. Any unbound substances were washed away, and an enzyme-linked polyclonal antibody specific for IL-6 was introduced. After incubation for 2 hours at room temperature, the plates were washed, a substrate solution was added, and color development was stopped after 25 minutes at room temperature. A microplate reader was then used to determine colorimetric densities at $570 \mathrm{~nm}$ and $450 \mathrm{~nm}$ for each sample. Results were calculated from a standard curve generated by a parametric 
logistic curve fit and expressed in $\mathrm{pg} / \mathrm{mL}$ of serum. The standard curve used 8 concentrations ranging from $1.5 \mathrm{pg} / \mathrm{mL}$ to $200 \mathrm{pg} / \mathrm{mL}$. Twenty plates were used for the experiment; the intra-assay coefficient of variation (CV) had a median of $6 \%$, and the interassay variability of the control samples had a CV of $7 \%$. The lower limit of detection as determined by the manufacturer is $0.7 \mathrm{pg} / \mathrm{mL}$.

\section{Control variables}

Standard questions on demographics were asked, including age and sex. Smoking status was classified into never smokers, former smokers, and those who were currently smoking. Tumor sites were classified into 3 groups, a) larynx, b) oropharynx, hypopharynx, nasopharynx, or unknown primary, and c) oral cavity or sinus. Tumor stages were measured by using the American Joint Commission on Cancer (AJCC) staging classification system ${ }^{23}$ and grouped into stage 0 , I, and II versus stage III and IV. Comorbidities were measured by using the Adult Comorbidity Evaluation-27 and grouped into none or mild comorbidities versus moderate or severe comorbidities. ${ }^{24,25}$ Treatments were classified as surgery only, radiation only, surgery and radiation, radiation and chemotherapy, surgery, radiation and chemotherapy, or unknown/no treatment. There were no chemotherapy-only patients. Because recurrence was an outcome variable, those treatments received after a recurrence were not classified, although treatments for those with persistent disease were included.

\section{Outcome variables-tumor recurrence and survival}

Recurrence dates were abstracted from medical records and data collection forms by the study research assistants, and notations were made about local recurrence, regional recurrence, or distant recurrence/metastatic disease. Data collection forms allowed for serial entries of recurrence. Patients for whom the treatment never rendered tumor free were assigned a recurrence time of 1 day. By contacting patients every 3 months, staff kept track of patient status (dead or alive). For those patients who were lost to follow-up, the Social Security Death Master File was used to determine whether and when they had died. Patients lost to follow-up and not found on the Social Security Death Master File were assumed alive as of February 1, 2007.

\section{Statistical Analysis}

Means and frequency distributions were examined for all variables. Associations between serum IL-6 and control variables (age, sex, smoking, cancer site, cancer stage, comorbidities, and treatments) were assessed by using analysis of variance. Because the data were not normally distributed, medians instead of means were given for serum IL-6. For univariate and multivariate analyses, serum IL-6 was treated as a continuous variable after log transformation [ln(IL-6 + 2)]. KaplanMeier plots and the log-rank tests were used to compare quartiles of serum IL-6 with recurrence and survival. Univariate and multivariate Cox proportional hazards models were used to study the relation between serum IL-6, control variables, and time to recurrence and death. Time to recurrence and death was measured from the pretreatment blood draw date.

\section{RESULTS \\ Description of the Sample Explanatory and Outcome Variables}

The median serum IL-6 level was $13 \mathrm{pg} / \mathrm{mL}$ (range, 0 -453). The 2 -year recurrence rate was $35.2 \%$ (standard error, $2.67 \%$ ). The 2 -year death rate was $26.5 \%$ (standard error, 2.26\%). The median follow-up time was 783 days (range, 0 -1438).

\section{Control Variables}

The mean patient age was 59 years (standard deviation, 11). Most patients were men, were current or former smokers, had cancer of the pharynx/unknown primary, had stage III or IV cancer, and had no or mild comorbidities. Because most patients had advanced disease, the most common treatment regimen was combined radiation and chemotherapy (41\%), followed by combined surgery, radiation, and chemotherapy (19\%), and the rest had surgery only, radiation only, radiation and surgery, or unknown/no treatment.

Older persons were more likely to have increased serum IL-6 levels than younger persons $(P=.008)$. Current and former smokers were more likely to have higher serum IL-6 levels than nonsmokers $(P<.001)$. Those with stage III and stage IV cancers had higher levels of serum IL- 6 than those with stage 0 , I, or II cancers $(P=.002)$. Those with moderate or severe comorbidities had higher serum IL-6 levels than those with no or mild comorbidities $(P<.001)$. There was no association between serum IL- 6 and sex, cancer site, or treatment type (Table 1).

\section{Serum IL-6 and Control Variables as Independent Predictors of Recurrence}

Figure 1 shows the Kaplan-Meier curve for the independent association between serum IL-6 (stratified by quartile) and recurrence. Those with the lowest quartiles of pretreatment serum IL-6 had fewer recurrences than those with the highest quartiles, 
TABLE 1

Description of Control Variables and Association With Pretreatment Serum Interleukin-6 ( $=444)$

\begin{tabular}{|c|c|c|c|c|c|}
\hline \multirow[b]{2}{*}{ Control Variable } & \multirow[b]{2}{*}{ No. } & \multirow[b]{2}{*}{$\%$} & \multicolumn{2}{|c|}{ Serum IL-6 (pg/mL) } & \multirow[b]{2}{*}{$P$} \\
\hline & & & Median & (5th, 95th \%) & \\
\hline \multicolumn{6}{|l|}{ Age } \\
\hline$\leq 58$ & 220 & 50 & 12 & $(1,66)$ & \multirow{2}{*}{.008} \\
\hline$>58$ & 224 & 50 & 14 & $(1,127)$ & \\
\hline \multicolumn{6}{|l|}{ Sex } \\
\hline Men & 350 & 79 & 13 & $(1,114)$ & \multirow[t]{2}{*}{.770} \\
\hline Women & 94 & 21 & 11 & $(2,114)$ & \\
\hline \multicolumn{6}{|l|}{ Smoking } \\
\hline Never & 76 & 17 & 9 & $(1,31)$ & \multirow{3}{*}{$<.001$} \\
\hline Former & 251 & 57 & 14 & $(1,125)$ & \\
\hline Current & 117 & 26 & 15 & $(3,111)$ & \\
\hline \multicolumn{6}{|l|}{ Cancer site } \\
\hline Oral cavity & 100 & 22 & 13 & $(2,99)$ & \multirow{3}{*}{.590} \\
\hline Pharynx & 230 & 52 & 12 & $(1,122)$ & \\
\hline Larynx & 114 & 26 & 14.5 & $(2,125)$ & \\
\hline \multicolumn{6}{|l|}{ Cancer Stage } \\
\hline Stage 0, I, II & 89 & 20 & 9 & $(1,97)$ & \multirow{3}{*}{.002} \\
\hline Stage III & 70 & 16 & 12.5 & $(1,64)$ & \\
\hline Stage IV & 285 & 64 & 14 & $(2,125)$ & \\
\hline \multicolumn{6}{|l|}{ Comorbidity } \\
\hline None or mild & 295 & 66 & 10 & $(1,84)$ & \multirow[t]{2}{*}{$<.001$} \\
\hline Moderate or severe & 149 & 34 & 18 & $(4,135)$ & \\
\hline \multicolumn{6}{|l|}{ Treatment } \\
\hline Surgery only & 63 & 14 & 11 & $(2,58)$ & \multirow{6}{*}{.420} \\
\hline Radiation only & 50 & 11 & 12 & $(3,174)$ & \\
\hline Surgery+radiation & 46 & 10 & 17 & $(2,84)$ & \\
\hline Radiation+chemotherapy & 180 & 41 & 12 & $(1,99)$ & \\
\hline All treatment & 83 & 19 & 13 & $(1,125)$ & \\
\hline Unknown treatment or none & 22 & 5 & 18 & $(1,225)$ & \\
\hline
\end{tabular}

and the second and third quartiles fell in between. The results of the univariate and multivariate Cox proportional hazards regression models for recurrence are presented in Table 2. Univariate analyses showed that higher pretreatment serum IL-6 was significantly associated with recurrence. Multivariate analyses showed that higher pretreatment serum IL-6 levels remained significantly associated with recurrence, even after controlling for the other variables $(\mathrm{HR}=1.32 ; 95 \% \mathrm{CI}, 1.11-1.58 ; P=.002)$. Cancer site (oral/sinus) was also significantly associated with recurrence in the multivariate model. Type of treatment was not included in the final model, because treatment was highly correlated with cancer site and stage, and did not change the results when it was included (other than attenuating stage); hence, the most parsimonious model is presented.

\section{Serum IL-6 and Control Variables as Independent Predictors of Survival}

Figure 2 shows the Kaplan-Meier curve for the independent association between serum IL-6 (stratified

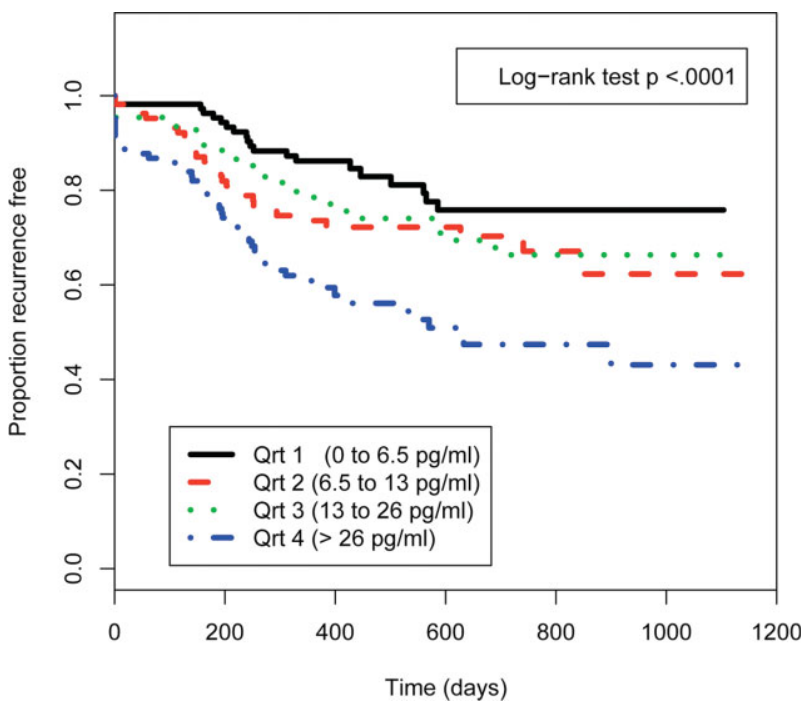

FIGURE 1. A Kaplan-Meier plot is stratified by quartile (Qrt) of pretreatment serum interleukin-6 for recurrence events $(\mathrm{N}=444)$.

by quartile) and survival. Similar to Figure 1, those with the lowest quartiles of pretreatment serum IL-6 had better survival than those with the highest quartiles, with others falling in between. Results of univariate and multivariate Cox proportional hazards regression models for survival are presented in Table 3. Univariate analysis showed that serum IL-6, age, smoking status, cancer stage, and comorbidities were significantly associated with survival. Multivariate analysis showed that higher pretreatment serum IL-6 levels were significantly associated with survival $(\mathrm{HR}=1.22 ; 95 \% \mathrm{CI}, 1.02-1.46, P=.030)$. Older age, smoking, cancer site (oral/sinus), cancer stage, and comorbidities were also independently associated with poorer survival in the multivariate analysis, whereas sex was not associated with survival. Again, treatment type was not included in the final model, because it was highly correlated with cancer site and stage, and treatment type did not greatly change results when it was included (other than attenuating stage).

\section{DISCUSSION}

To our knowledge, this is the largest prospective study that demonstrates an independent association, when controlling for other prognostic factors, between pretreatment serum IL-6 levels and both recurrence and survival among HNSCC patients. The temporal association between pretreatment serum IL-6 and both recurrence and survival confirms that serum IL-6 may be a valuable prognostic biomarker in this population. Patients with high levels of 
TABLE 2

Univariate and Multivariate Hazard Ratios of Serum Interleukin (IL)-6 From Cox Proportional Hazards Regression Models for Recurrence Events

\begin{tabular}{|c|c|c|c|c|c|c|}
\hline \multirow[b]{2}{*}{ Variable Name } & \multicolumn{3}{|c|}{ Univariate Model Results } & \multicolumn{3}{|c|}{ Multivariate Model Results } \\
\hline & Hazard Ratio & $95 \% \mathrm{CI}$ & $P$ & Hazard Ratio & $95 \% \mathrm{CI}$ & $P$ \\
\hline Log serum IL-6 & 1.42 & $1.21-1.66$ & $<.001$ & 1.32 & $1.11-1.58$ & .002 \\
\hline Age, decades & 1.15 & $0.98-1.34$ & .091 & 1.14 & $0.96-1.35$ & .150 \\
\hline Men vs women & 1.11 & $0.72-1.71$ & .630 & 1.17 & $0.75-1.83$ & .490 \\
\hline Current smoker vs never & 1.72 & $0.97-3.04$ & .062 & 1.39 & $0.76-2.53$ & .280 \\
\hline Former smoker vs never & 1.41 & $0.83-2.38$ & .200 & 1.15 & $0.66-2.02$ & .620 \\
\hline Pharynx cancer site vs oral & 0.67 & $0.45-1.01$ & .053 & 0.62 & $0.40-0.96$ & .031 \\
\hline Larynx cancer site vs oral & 0.64 & $0.40-1.03$ & .066 & 0.59 & $0.36-0.97$ & .036 \\
\hline Stage III vs 0-I & 1.58 & $0.85-2.94$ & .150 & 1.77 & $0.93-3.36$ & .081 \\
\hline Stage IV vs 0-I & 1.62 & $0.98-2.68$ & .063 & 1.60 & $0.93-2.76$ & .089 \\
\hline Comorbidity, moderate/severe vs none/mild & 1.26 & $0.88-1.80$ & .210 & 1.08 & $0.74-1.59$ & .680 \\
\hline
\end{tabular}

$\mathrm{N}=444: 130$ events and 314 censored. For IL-6, the hazard ratio is for a unit increase in $\ln (\mathrm{IL}-6+2 \mathrm{pg} / \mathrm{mL})$.

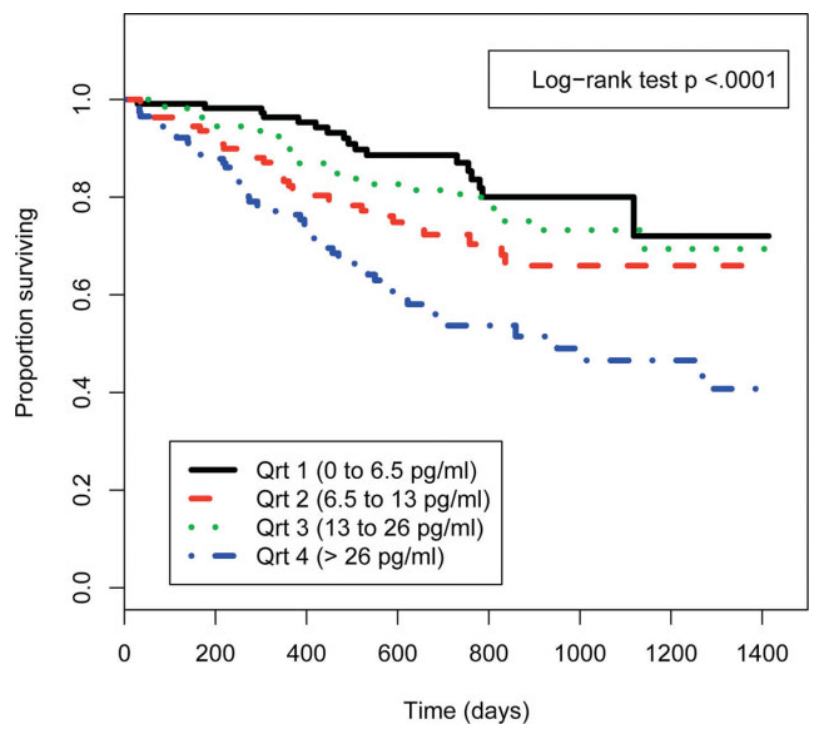

FIGURE 2. A Kaplan-Meier plot is stratified by quartile (Qrt) of pretreatment serum interleukin-6 for survival events $(\mathrm{N}=444)$.

pretreatment serum IL-6 levels may benefit from closer follow-up to have a better chance of identifying recurrences at an early stage. Those with higher pretreatment serum IL-6 levels could be candidates for more aggressive intervention to prolong survival.

Increasing evidence implicating serum IL-6 as a prognostic marker for HNSCC and other cancer types is emerging in this and other studies. Studies in solid tumors (gastric, renal cell, colorectal, prostate, nonsmall cell lung, melanoma) as well as hematologic malignancies (myeloma, non-Hodgkin's lymphoma) indicate the potential prognostic significance of increased pretreatment serum IL-6 levels. Several studies have demonstrated associations between serum IL-6 genotypes and cancer risk. ${ }^{26,27}$ Variations in individual inflammatory response could explain the considerable variations in recurrence and survival rates among patients with similar tumor grades and stages. ${ }^{26}$

The mechanism by which serum IL-6 contributes to or reflects cancer progression and biology is likely due to its dual effects on tumor initiation by paracrine or autocrine mechanisms and to its additional inhibitory effects on the immune response directed against the tumor. ${ }^{28-30}$ IL-6 inhibits dendritic cell differentiation, thus inducing immune tolerance of tumors and facilitating metastatic spread. ${ }^{31}$ The source of IL-6 in cancer patients' sera has been shown predominately to emanate from the tumor itself, but monocytes in head and neck cancer patients have been shown to secrete higher levels than monocytes from normal individuals. ${ }^{32}$ It is well documented that monocyte functional abnormalities and impaired cellular immunity are frequent and early characteristics of patients with head and neck cancer. When taken together with our prior findings that tumor-associated macrophages predict aggressive behavior in HNSCC, ${ }^{33}$ an interesting hypothesis is raised, which proposes that IL-6 secretion from both tumor and monocytes in the tumor microenvironment results in an immune-tolerant situation that allows the tumor to thrive.

Unpublished data from our laboratory have further confirmed the impairment of dendritic cell maturation in head and neck cancer patients secondary to IL-6 signaling. Park et al found that IL-6 inhibits in vivo dendritic cell differentiation through STAT-3 activation. ${ }^{31}$ Interestingly, of the STAT family members, STAT-3 is most frequently associated with neoplasia, and it has been found to be constitutively 
TABLE 3

Univariate and Multivariate Hazard Ratios of Serum Interleukin (IL)-6 From Cox Proportional Hazards Regression Models for Death Events

\begin{tabular}{|c|c|c|c|c|c|c|}
\hline \multirow[b]{2}{*}{ Variable Name } & \multicolumn{3}{|c|}{ Univariate Model Results } & \multicolumn{3}{|c|}{ Multivariate Model Results } \\
\hline & Hazard Ratio & $95 \% \mathrm{CI}$ & $P$ & Hazard Ratio & $95 \% \mathrm{CI}$ & $P$ \\
\hline Log serum IL-6 & 1.49 & $1.27-1.74$ & $<.001$ & 1.22 & $1.02-1.46$ & .030 \\
\hline Age, decades & 1.47 & $1.26-1.73$ & $<.001$ & 1.48 & $1.23-1.77$ & $<.001$ \\
\hline Men vs women & 1.23 & $0.78-1.94$ & .370 & 1.36 & $0.84-2.19$ & .210 \\
\hline Current smoker vs never & 2.69 & $1.38-5.23$ & .004 & 2.34 & $1.17-4.69$ & .016 \\
\hline Former smoker vs never & 2.30 & $1.22-4.33$ & .010 & 1.82 & $0.94-3.54$ & .076 \\
\hline Pharynx cancer site vs oral & 0.69 & $0.46-1.05$ & .082 & 0.59 & $0.38-0.91$ & .019 \\
\hline Larynx cancer site vs oral & 0.63 & $0.38-1.03$ & .066 & 0.47 & $0.28-0.79$ & .004 \\
\hline Stage III vs 0-II & 1.44 & $0.75-2.77$ & .280 & 1.81 & $0.92-3.56$ & .087 \\
\hline Stage IV vs 0 -II & 1.70 & $1.01-2.86$ & .045 & 1.87 & $1.07-3.27$ & .029 \\
\hline Comorbidity, moderate/severe vs none/mild & 1.91 & $1.34-2.73$ & $<.001$ & 1.51 & $1.03-2.21$ & .034 \\
\hline
\end{tabular}

$\mathrm{N}=444: 124$ events and 320 censored. For IL-6, the hazard ratio is for a unit increase in $\ln (\mathrm{IL}-6+2 \mathrm{pg} / \mathrm{mL})$.

active in HNSCC. Conversely, inhibition of STAT-3 function results in growth retardation in HNSCC. ${ }^{34-36}$ Although active epidermal growth factor receptor (EGFR) is capable of inducing STAT-3 phosphorylation, ${ }^{30}$ the incidence of EGFR expression in HNSCC varies greatly, whereas STAT-3 phosphorylation is a more common event. ${ }^{30}$ In an important finding, Sriuranpong et al showed that IL-6-mediated activation of STAT-3 in HNSCC occurs via autocrine/paracrine stimulation of the gp130 receptor and is independent of EGFR activation. ${ }^{30}$ These data support the hypothesis that disruption of the IL-6/gp130 signaling pathway that prevents STAT-3 activation could be a novel therapeutic target for HNSCC, because it may reduce tumor growth and allow for improved dendritic cell maturation and immune recognition of tumors. At the same time, the interruption of this pathway could compromise wound healing, cytokine homeostasis, and immune response among head and neck cancer patients.

The development of HNSCC is likely to be associated with inflammation related to smoking and alcohol intake, or with exposure to the human papillomavirus type 16, or with other nonspecific agents that could manifest as comorbidities. Thus, it was not surprising that, when they were compared with nonsmokers, both current and former smokers had higher serum IL-6 levels and decreased survival. Although no serum acute-phase protein levels or inflammatory diseases were assessed, comorbidities that may be associated with inflammatory disease were also associated with serum IL-6, and they predicted recurrence and survival.

Although not associated with serum IL-6, cancer site (oral/sinus) predicted recurrence and survival. This expected finding is well known and reflected in
SEER data, which show that laryngeal cancer patients have better 5 -year survival rates $(64.1 \%)$ than oral/ pharyngeal cancer patients $(58.8 \%)$, and that more oral/pharyngeal cancer patients present at a later cancer stage. ${ }^{37}$ Because a higher cancer stage may be associated with greater inflammation, ulceration, and greater inflammatory response, it is not surprising that those at a higher cancer stage were more likely to have higher serum IL-6 levels than those at lower stages, and this has been demonstrated in other studies. $^{7,20}$ Cancer stage also significantly predicted poor survival; however, there was little variability, because the vast majority $(80 \%)$ of patients in the sample were stage III or IV cancer patients. Treatment was not associated with serum IL- 6 levels, and was omitted from the final model because of the high correlation with cancer site and stage. When included in the model, treatment did not alter results (other than attenuating cancer stage) and was not associated with recurrence, and only 1 form of treatment (the combination of surgery, radiation, and chemotherapy) was associated with survival. The lack of treatment effect was likely because there was little variability in treatment, as most patients had advanced disease, and all patients were from tertiary care centers that provided state-of-the-art treatment for their particular cancer site and stage.

Age-associated decreases in immune competence are well known, and an increase in serum IL-6 levels with age was an expected observation. Although women generally live longer than men, ${ }^{38}$ there were no sex effects for recurrence or survival. Two-year recurrence and survival rates were similar to those found in other studies. ${ }^{39,40}$ The median serum IL-6 level of the sample was $13 \mathrm{pg} / \mathrm{mL}$ (range, $0 \mathrm{pg} / \mathrm{mL}-453 \mathrm{pg} / \mathrm{mL}$ ), which was lower than the 
mean of $19.5 \mathrm{pg} / \mathrm{mL}$ (range, $0 \mathrm{pg} / \mathrm{mL}-313 \mathrm{pg} / \mathrm{mL}$ ) found in a smaller sample $(\mathrm{N}=90)$ of HNSCC patients. ${ }^{7}$ Although the smaller study found the mean serum IL-6 of healthy controls to be $6.0 \mathrm{pg} / \mathrm{mL}$ (range, $0 \mathrm{pg} / \mathrm{mL}-52 \mathrm{pg} / \mathrm{mL}$ ), no normal control subjects were available for comparison in this study. Although natural IL-6 inhibitors may be present in some patients' sera, so that low IL-6 levels may be false-negative, we did not screen for these in this study.

Pretreatment serum IL- 6 predicted cancer recurrence and survival within a large sample of HNSCC patients, when other prognostic factors were statistically controlled, and, thus, may provide a valuable prognostic biomarker for HNSCC patients. Identifying those at risk for recurrence may allow earlier identification and treatment of disease relapse. Higher pretreatment serum IL-6 levels may also identify candidates for more aggressive surveillance and treatment. Further studies to determine the biologic basis for this association may also provide new targets for development of innovative, biologically based adjuvant therapy in this challenging disease.

\section{REFERENCES}

1. Akira S, Taga T, Kishimoto T. Interleukin-6 in biology and medicine. Adv Immunol. 1993;54:1-78.

2. Hirano T, Akira S, Taga T, Kishimoto T. Biological and clinical aspects of interleukin 6. Immunol Today. 1990;11:443449.

3. Le JM, Vilcek J. Interleukin 6: a multifunctional cytokine regulating immune reactions and the acute phase protein response. Lab Invest. 1989;61:588-602.

4. Ramadori G, Christ B. Cytokines and the hepatic acutephase response. Semin Liver Dis. 1999;19:141-155.

5. Muraoka K, Shimizu K, Sun X, et al. Hypoxia, but not reoxygenation, induces interleukin 6 gene expression through NF-kappa B activation. Transplantation. 1997;63: 466-470.

6. Teknos TN, Islam M, Arenberg DA, et al. The effect of tetrathiomolybdate on cytokine expression, angiogenesis, and tumor growth in squamous cell carcinoma of the head and neck. Arch Otolaryngol Head Neck Surg. 2005;131:204-211.

7. Riedel F, Zaiss I, Herzog D, Gotte K, Naim R, Hormann K. Serum levels of interleukin-6 in patients with primary head and neck squamous cell carcinoma. Anticancer Res. 2005;25:2761-2765.

8. van Bokhorst-de van der Schuer MA, von Blomberg-vander Flier BM, Kuik DJ, et al. Survival of malnourished head and neck cancer patients can be predicted by human leukocyte antigen-DR expression and interleukin-6/tumor necrosis factor-alpha response of the monocyte. JPEN $J$ Parenter Enteral Nutr. 2000;24:329-336.

9. de Luis DA, Izaola O, Cuellar L, et al. Effect of c-reactive protein and interleukins blood levels in postsurgery arginine-enhanced enteral nutrition in head and neck cancer patients. Eur J Clin Nutr. 2003;57:96-99.

10. Woods KV, El-Naggar A, Clayman GL, Grimm EA. Variable expression of cytokines in human head and neck squamous cell carcinoma cell lines and consistent expression in surgical specimens. Cancer Res. 1998;58:3132-3141.
11. Klampfer L. Signal transducers and activators of transcription (STATs): novel targets of chemopreventive and chemotherapeutic drugs. Curr Cancer Drug Targets. 2006;6:107-121.

12. Alvarez JV, Greulich H, Sellers WR, Meyerson M, Frank DA. Signal transducer and activator of transcription 3 is required for the oncogenic effects of non-small-cell lung cancer-associated mutations of the epidermal growth factor receptor. Cancer Res. 2006;66:3162-3168.

13. Yin W, Cheepala S, Roberts JN, Syson-Chan K, DiGiovanni J, Clifford JL. Active Stat3 is required for survival of human squamous cell carcinoma cells in serum-free conditions. Mol Cancer. 2006;5:15.

14. Kusaba T, Nakayama T, Yamazumi K, et al. Activation of STAT3 is a marker of poor prognosis in human colorectal cancer. Oncol Rep. 2006;15:1445-1451.

15. Wu CW, Wang SR, Chao MF, et al. Serum interleukin-6 levels reflect disease status of gastric cancer. Am J Gastroenterol. 1996;91:1417-1422.

16. Tsukamoto T, Kumamoto Y, Miyao N, Masumori N, Takahashi A, Yanase M. Interleukin-6 in renal cell carcinoma. $J$ Urol. 1992;148:1778-1781; discussion 1781-1782.

17. Nakashima J, Tachibana M, Horiguchi Y, et al. Serum interleukin 6 as a prognostic factor in patients with prostate cancer. Clin Cancer Res. 2000;6:2702-2706.

18. Plante M, Rubin SC, Wong GY, Federici MG, Finstad CL, Gastl GA. Interleukin-6 level in serum and ascites as a prognostic factor in patients with epithelial ovarian cancer. Cancer. 1994;73:1882-1888.

19. Zhang GJ, Adachi I. Serum interleukin-6 levels correlate to tumor progression and prognosis in metastatic breast carcinoma. Anticancer Res. 1999;19:1427-1432.

20. De Schutter H, Landuyt W, Verbeken E, Goethals L, Hermans R, Nuyts S. The prognostic value of the hypoxia markers CA IX and GLUT 1 and the cytokines VEGF and IL 6 in head and neck squamous cell carcinoma treated by radiotherapy $+/-$ chemotherapy. BMC Cancer. 2005;5:42.

21. St John MA, Li Y, Zhou X, et al. Interleukin 6 and interleukin 8 as potential biomarkers for oral cavity and oropharyngeal squamous cell carcinoma. Arch Otolaryngol Head Neck Surg. 2004;130:929-935.

22. Gallo O, Gori AM, Attanasio M, et al. Interleukin-6 and acute-phase proteins in head and neck cancer. Eur Arch Otorhinolaryngol. 1995;252:159-162.

23. American Joint Committee on Cancer; Greene F, Page D, Fleming I, et al, eds. AJCC cancer staging manual. 6th Ed. New York: Springer-Verlag; 2002.

24. Piccirillo JF, Tierney RM, Costas I, Grove L, Spitznagel EL Jr. Prognostic importance of comorbidity in a hospitalbased cancer registry. JAMA. 2004;291:2441-2447.

25. Piccirillo JF, Costas I, Claybour P, Borah AJ, Grove L, Jeffe D. The measurement of comorbidity by cancer registries. $J$ Registry Manage. 2003;30:8-15.

26. Leibovici D, Grossman HB, Dinney CP, et al. Polymorphisms in inflammation genes and bladder cancer: from initiation to recurrence, progression, and survival. J Clin Oncol. 2005;23:5746-5756.

27. Tan $\mathrm{D}, \mathrm{Wu} \mathrm{X}, \mathrm{Hou} \mathrm{M}$, et al. Interleukin-6 polymorphism is associated with more aggressive prostate cancer. $J$ Urol. 2005;174:753-756.

28. Thomas GR, Chen Z, Leukinova E, Van Waes C, Wen J. Cytokines IL-1 alpha, IL-6, and GM-CSF constitutively secreted by oral squamous carcinoma induce down-regulation of CD80 costimulatory molecule expression: restoration by interferon gamma. Cancer Immunol Immunother. 2004;53:33-40. 
29. Tanner J, Tosato G. Impairment of natural killer functions by interleukin 6 increases lymphoblastoid cell tumorigenicity in athymic mice. J Clin Invest. 1991;88:239-247.

30. Sriuranpong V, Park JI, Amornphimoltham P, Patel V, Nelkin $\mathrm{BD}$, Gutkind JS. Epidermal growth factor receptor-independent constitutive activation of STAT3 in head and neck squamous cell carcinoma is mediated by the autocrine/ paracrine stimulation of the interleukin 6/gp130 cytokine system. Cancer Res. 2003;63:2948-2956.

31. Park SJ, Nakagawa T, Kitamura H, et al. IL-6 regulates in vivo dendritic cell differentiation through STAT3 activation. J Immunol. 2004;173:3844-3854.

32. Gallo O, Gori AM, Attanasio M, et al. Interleukin-1 beta and interleukin-6 release by peripheral blood monocytes in head and neck cancer. Br J Cancer. 1993;68:465-468.

33. Marcus B, Arenberg D, Lee J, et al. Prognostic factors in oral cavity and oropharyngeal squamous cell carcinoma. Cancer. 2004;101:2779-2787.

34. Grandis JR, Drenning SD, Chakraborty A, et al. Requirement of Stat3 but not Statl activation for epidermal growth factor receptor-mediated cell growth in vitro. J Clin Invest. 1998;102:1385-1392.
35. Grandis JR, Drenning SD, Zeng Q, et al. Constitutive activation of Stat3 signaling abrogates apoptosis in squamous cell carcinogenesis in vivo. Proc Natl Acad Sci U S A. 2000;97:4227-4232.

36. Grandis RJ, Zeng Q, Drenning SD. Epidermal growth factor receptor-mediated stat3 signaling blocks apoptosis in head and neck cancer. Laryngoscope. 2000;110:868874.

37. Ries LAG, Harkins D, Krapcho M, et al, eds. SEER cancer statistics review, 1975-2003. Bethesda, MD: National Cancer Institute; 2006.

38. Owens IP. Ecology and evolution. Sex differences in mortality rate. Science. 2002;297:2008-2009.

39. Pytynia KB, Grant JR, Etzel CJ, Roberts DB, Wei Q, Sturgis EM. Matched-pair analysis of survival of never smokers and ever smokers with squamous cell carcinoma of the head and neck. J Clin Oncol. 2004;22:3981-3988.

40. Tartour E, Deneux L, Mosseri V, et al. Soluble interleukin-2 receptor serum level as a predictor of locoregional control and survival for patients with head and neck carcinoma: results of a multivariate prospective study. Cancer. 1997; 79:1401-1408. 